\title{
Study of Ghrelinand LeptinHormones Changes in Obese Postmenopausal Patients
}

\author{
Abeer Nasser M AL Ghalbi \\ Teaching Assistant, Department of Pathology, Taif Faculty of Medicine, Taif University, Taif, ksa
}

\begin{abstract}
Obesity is a community health problem affecting over one billion adult persons worldwide. Ghrelin and leptin levels are influenced by body fat and pubertal stage. Leptin is known to play an important role in the pathogenesis of obesity. The objective of this study was to evaluate the levels of the ghrelin and leptin in attempt to assess their role in the pathogenesis of obesity inpostmenopausal women. Methods: This study was performed on sixty postmenopausal obese patients and 30 healthy controls. All obese patients have body mass index $(B M I) \geq 30 \mathrm{Kg} / \mathrm{m} 2$. Among healthy persons, those with a $B M I<30 \mathrm{~kg} / \mathrm{m}^{2}$ were selected as the control group. Ghrelin and leptin concentrations were measured by ELISA method. Results:Leptin levels were significantly higher in obese postmenopausal women compared to controls. On the contrary, ghrelin levels were significantly lower in postmenopausal obese patients in comparison with the control group.Present study revealed significant negative correlation between ghrelin and BMI (P $\leq 0.001)$, and revealed significant positive correlation between leptin and BMI (P $\leq 0.001)$. Conclusion: From these results, the increase in leptin levels together with the decrease of ghrelin levelsprobably fails to suppress appetite in obese postmenopausal women and leptin concentration could be considered a good marker of the amount of body fat in obese conditions and could be used as a line of treatment.
\end{abstract}

Keywords: Ghrelin hormone - Leptin hormone - Obesity - appetite in obese postmenopausal-Body mass index (BMI)

\section{Introduction}

Obesity is now dramatically risingworldwide.It is a major risk factor for insulin resistance, type 2 diabetes, heart disease, orthopedic problems, and many other chronic diseases $[1,2]$.The etiology is multifactorial, with genetic, socioeconomic, behavioral or psychological influences such as poor dietary habits, a sedentary lifestyle, and environmental which encourages unhealthy behaviors with an increase in the related morbidity and mortality[3].Adipocytes produce and secrete several proteins that act as hormones, responsible for the regulation of energy intake and expenditure. Ghrelin and leptin are two hormones playing an important role in the regulation of food intake and body weight[4-6].

Leptinis a 67 amino-residue peptide, the protein product of the obesity (ob) gene and plays a key role in regulating longterm energy homeostasis and body fat stores[7]. It isa neurohormone that is secreted byadipocytes and binds to receptors in the hypothalamus[8]. Following release into the circulation, leptin crosses the blood-brain barrier and binds to leptin receptors in the hypothalamus; this peptide controls energy metabolism at the level of hypothalamus by suppresses the food intake and stimulating energy expenditure[7, 9 and 10].Food restriction lower leptin levelsandthis is reversed by re-feeding becausethe main function of leptin is to signal starvation when levels are low $[6,11]$. It levels are influenced by the amount of body fat, as they are found high in obese and low in lean individuals $[9,12]$.

Ghrelin is a 28 amino-residue peptide andsynthesized predominantly by the stomach. Substantially lower amounts were detected in bowel, pancreas, kidneys, the immune system, placenta, testes, pituitary, lung, and hypothalamus. Physiologically, ghrelin secretion is inhibited by food intake and stimulated during fasting and after weight loss[13, 14]. Ghrelin circulates in both acylated and desacylated forms.
Acylation is essential for orexigenic (appetite stimulating) activity, whereas desacyl ghrelin has recently been shown to exert an anorexigenic effect[15].Among several other biological functions, ghrelin was found to produce positive energy balance as it plays a role in the regulation of energy balance and attenuates leptin-induced reduction in food intake and body weight $[6,16,17]$.Ghrelin levels are lower in obese subjects compared to lean, and weight loss result in an increase in its level. The highest levels of ghrelin are found during early postnatal life, when growth hormone begins to exert its effects on growth. Pre-pubertal children have higher ghrelin concentrations than those in puberty $[18,19]$

\section{Subjects and Methods}

\subsection{Subjects}

The present study was carried out on sixtypostmenopausal obese females (obesitywas defined according to WHO criteria 2010 as BMI greater than orequal to $30 \mathrm{~kg} / \mathrm{m} 2$ and a waist circumference equal to or above 90 percentile of their age) with matched age range 49-67yearsselected from outpatient clinics of Obstetrics and Gynecology Departments of king faisal hospitaland al hada Hospitals , KSAifromJanuary 2014tillOctober 2014.In addition thirty apparentlyhealthy individualswith average body weight, with matched age range 46-65years, and were enrolled in thestudy as a controls, their BMI $<30 \mathrm{~kg} / \mathrm{m}^{2}$. They were all at least 12yearspostmenopausal.All women had similar lifestyle with no significant physicaltraining program before beginning the study.Exclusion criteria:Persons with a known history of primary hyperlipidemia, diabetes mellitus type 2 or secondary obesity were excluded from the study.

\subsection{Methods}

After their consent, all subjects were subjected to:Full history taking with particular emphasis on age, familyhistory, history of any systemic diseases e.g. diabetes, 


\section{International Journal of Science and Research (IJSR) ISSN (Online): 2319-7064 \\ Index Copernicus Value (2013): 6.14 | Impact Factor (2014): 5.611}

hypertension,dyslipidemia or history of any associated diseases and any drug intake, full medical examinationand clinical examination. All women were subjected to:Detailed medical history, menstrual history including age, duration since menopause, and history of fertility. Anthropometric measurements:Measurements were performed after an overnight fast. Bodyweight was measured on calibrated balances or electronic scalesto the nearest $0.1 \mathrm{~kg}$. Body height was measured to the nearestcentimeter. BMI was calculated as body weight in kilograms $(\mathrm{kg})$ dividedby body height (meters) squared(m2) expressed as $\mathrm{Kg} / \mathrm{m} 2$. Using a tape measure,with the subject standing, the waist was measured as the narrowestcircumference between the lower costal margin andthe iliac crest. The hip was the maximum circumference atthe level of the femoral trochanters.

All participants were classified to overweight or obese usinginternational sex and age specific BMI cut-offs. BMI divided intothree groups according tothe criteria of theWorld Health Organization WHO; lean(BMI 18-24.5 kg/m2), overweight (BMI 25-29.5 kg/m2) and obese (BMI $\geq 30$ $\mathrm{kg} / \mathrm{m} 2$ ). Routine Laboratory Investigations:Lipid profile including total cholesterol (TC), serum triglycerides (TG), high density lipoprotein (HDL cholesterol) andlow density lipoprotein (LDLcholesterol).

\subsection{Quantitative measurement of human leptin by ELISA method:}

Specimen Collection: Early morning venous blood sample was collected from all subjects after an overnight fast (12-16 hr) in vacutainer tubes. Clotted samples were centrifuged at $3000 \mathrm{rpm}$ for 5 minutes and stored at $-20{ }^{\circ} \mathrm{C}$ till the time of assay of leptin.

Human leptin ELISAkit(Catalog No.: RD191001100) is a sandwich enzyme immunoassayfor the quantitative measurement of human leptin.It wassupplied byBioVendor GmbH, D-69120 Heidelberg, Germany.In the BioVendorhuman leptin ELISA kit, standards, quality controls and samplesare incubated in microplate wells precoated with polyclonal anti-human leptin antibody. After60 minutes incubation and washing, polyclonal anti-human leptin antibody, conjugated withhorseradish peroxidase (HRP) is added to the wells and incubated for 60 minutes withcaptured leptin. Following another washing step, the remaining HRP conjugate is allowed toreact with the substrate solution (TMB). The reaction is stopped by addition of acidic solutionand absorbance of the resulting yellow product is measured. The absorbance is proportional tothe concentration of leptin. A standard curve is constructed by plotting absorbance valuesagainst concentrations of standards, and concentrations of unknown samples are determinedusing this standard curve.

\subsection{Detection of Ghrelin Level by ELISA Method:}

Specimen Collection: Collect blood samples into the lavender vacutaner tubes, which contain EDTA and can collect blood/tube. Gently rock the lavender vacutaner tubes several times immediately after collection of blood for anticoagulation. Transfer the blood from the lavender vacutaner tubes to centrifuge tubes and gently rock for several times to inhibit the activity of proteinases. Centrifuge the blood at 1,600rpm 1,600 for 15 minutes at $4^{\circ} \mathrm{C}$ and kept at $-70^{\circ} \mathrm{C}$ till the time of assay.

Ghrelin levelwas measured by a commercially availableELISA kit supplied byDRG ${ }^{\circledR}$ Ghrelin (Human) ELISA International Inc., USA (Catalog No.: EIA-3706).This assay is anenzyme immunoassay kit is designed to detect a specific peptide and its related peptides based on the principle of "competitive" enzyme immunoassay. The standard curve was plotted using curve-fitting software capableof 4 parameter logistics to quantify the concentration of standardpeptide. A standard curve of a peptide with known concentration can beestablished accordingly. The peptide with unknown concentrations insamples can be determined by extrapolation from this standard curve.

\subsection{Statistical Analysis}

Data were collected, revised, coded and entered to the statistical package for social science (SPSS). The statistical analysis of the results was carried out according to the conventional standard statistical procedures using computed statistical analysis by SPSS, version 20.0. The quantitative data were presented as mean and standard deviations (mean \pm SD). All variables were tested for normality of distribution, Fisher's exact test and independent samples t-test ( $t$ value). The confidence interval was set to $95 \%$ and the margin of error accepted was adjusted to $5 \%$. So, the p-value was considered insignificant at the level of $>0.05$, significant at the level of $<0.05$ and highly significant at the level of $<$ 0.01 .

\section{Results}

The mean anthropometric (BMI,waist and hip) and lipid profile [Total cholesterol (TC), serum triglycerides (TG), high density lipoprotein (HDL cholesterol) andlow density lipoprotein (LDLcholesterol)] of two studied groups are presented intable 1 .

Table 1: Mean and SD values of the BMI, anthropometric parameters and lipid profile measured in the studied groups and their statistical significance using statistical Student's ttest.

\begin{tabular}{|c|c|c|c|}
\hline Variables & $\begin{array}{c}\text { Control } \\
\text { group }\end{array}$ & $\begin{array}{c}\text { Postmenopausal } \\
\text { obesegroup }\end{array}$ & Overall \\
\cline { 2 - 4 } & $\mathrm{n}=30$ & $\mathrm{n}=60$ & P-value \\
\hline BMI (Kg/m2 ) & $25.77 \pm 2.16$ & $39.5 \pm 6.59$ & 0.001 \\
\hline Waist (cm) & $70.22 \pm 0.88$ & $112.43 \pm 2.35$ & 0.001 \\
\hline Hip (cm) & $90.61 \pm 0.44$ & $119.89 \pm 2.23$ & 0.001 \\
\hline Cholesterol(mg/dl) & $169.5 \pm 37.1$ & $183.1 \pm 31.75$ & 0.001 \\
\hline TG(mg/dl) & $110.2 \pm 29.7$ & $150.3 \pm 45.3$ & 0.001 \\
\hline HDL(mg/dl) & $45.9 \pm 6.0$ & $33.8 \pm 9.2$ & 0.001 \\
\hline LDL(mg/dl) & $88.5 \pm 23.9$ & $109.4 \pm 30.2$ & 0.001 \\
\hline
\end{tabular}

As presented in table 1, Student's t-test was applied and statistically significant increase were observed on comparing BMI,waist, hip, TC,TGand LDL- c in postmenopausal obese group with compared withcontrol group.Both groups differedin HDL- $\mathrm{c}$ that was significantly higher incontrols than in obese patients. 


\section{International Journal of Science and Research (IJSR) \\ ISSN (Online): 2319-7064 \\ Index Copernicus Value (2013): 6.14 | Impact Factor (2014): 5.611}

Table 2: Statistically comparison between obese group andcontrols as regardleptin and ghrelin hormonesmeasured

\begin{tabular}{|l|c|c|c|}
\hline \multicolumn{1}{|c}{ in the study (Mean \pm SD) } \\
& $\begin{array}{c}\text { Control } \\
\text { group }\end{array}$ & $\begin{array}{c}\text { Postmenopausal } \\
\text { obesegroup }\end{array}$ & Overall \\
\cline { 2 - 4 } & $\mathrm{n}=30$ & $\mathrm{n}=60$ & P-value \\
\hline Leptin $(\mathrm{ng} / \mathrm{ml})$ & $10.3 \pm 2.9$ & $44.7 \pm 19.4$ & 0.001 \\
\hline Ghrelin $(\mathrm{ng} / \mathrm{ml})$ & $0.55 \pm 0.01$ & $0.24 \pm 0.02$ & 0.001 \\
\hline
\end{tabular}

As showed in table 2, a statistically significant increase was observed on comparing leptin in the obese group with the controls $(\mathrm{P} \leq 0.001)$. On the other hand, the mean ghrelin concentrationswere generally decreasing withincreasing body weight; it was evident that the levels wereremarkably higher among controls if they were comparedwith the obese groups, these differences werestatistically significant $(\mathrm{P} \leq$ $0.001)$.

Furthermore, we analyzed the relationshipsbetween the particular parameters in both groups (Figures 1-3). The mean leptin concentration in these two groups was positively correlated with $\mathrm{BMI}(\mathrm{r}=0.899, \mathrm{P} \leq 0.001)$. On the contrary, the currentstudy revealed significant negative correlation between ghrelinconcentration and $\mathrm{BMI}(\mathrm{r}=0.701$, $\mathrm{P} \leq 0.001)$ in the two groups.Also, present study revealed significantnegative correlation was detectedbetween the ghrelin and leptinlevels $(\mathrm{r}=0.603, \mathrm{P} \leq 0.001)$.

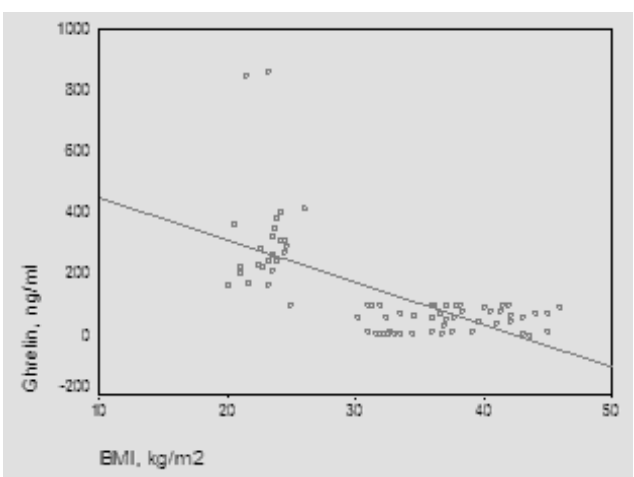

Figure 1: Correlation between ghrelin and BMI

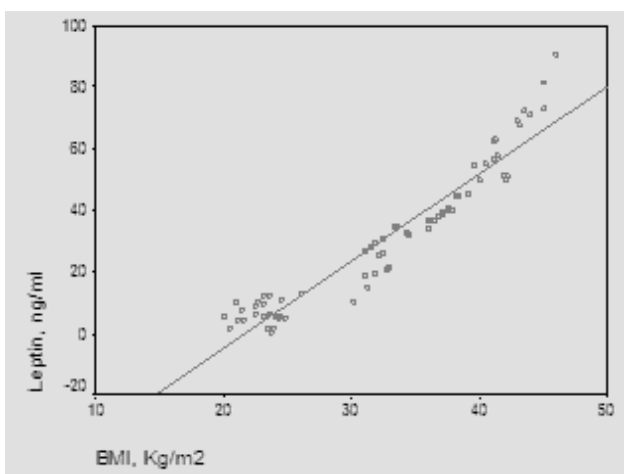

Figure 2: The correlation between leptin and BMI



Figure 3: Correlation between ghrelin and leptin

Table 3: Protective levelsof leptin against obesity and risky levels of ghrelin with obesity, leptin less than 9.5 (ng/ml)was protective against obesity and ghrelin less than $266(\mathrm{ng} / \mathrm{ml})$ was risky of obesity.

\begin{tabular}{|c|c|c|c|c|c|c|c|}
\hline Variables & Cut off point & AUC & Sensitivity & Specificity & + PPV & -NPV & P-value \\
\hline Leptin $(\mathrm{ng} / \mathrm{ml})$ & $>9.5$ & 0.884 & 100 & 72 & 87.7 & 100 & \\
\cline { 1 - 7 } Ghrelin $(\mathrm{ng} / \mathrm{ml})$ & 0.266 & 0.556 & 98 & 48 & 79 & 92.3 & $<0.001$ \\
\hline
\end{tabular}

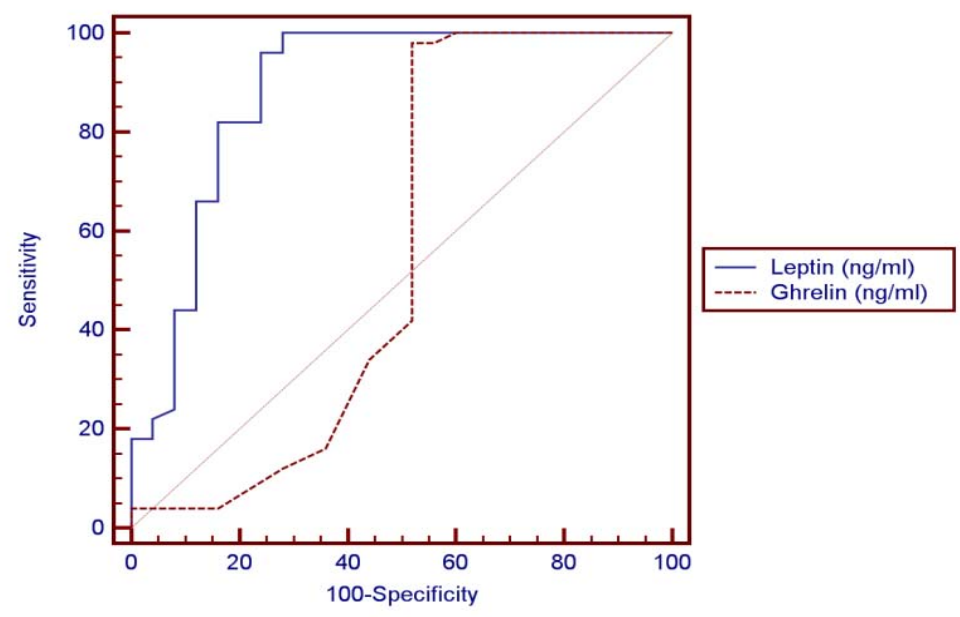

Figure 4: ROC curve of leptin and ghrelin 


\section{International Journal of Science and Research (IJSR) \\ ISSN (Online): 2319-7064 \\ Index Copernicus Value (2013): 6.14 | Impact Factor (2014): 5.611}

\section{Discussion}

The main objectives of the present study were designed first to compare ghrelin and leptinlevels in obese and non-obese post-menopausal women and second to investigate thecorrelation between obesity and two key hormones involved in the regulation of body weight homeostasis. In the current study, statistically significant increases wereobserved on comparing serum triglycerides and cholesterol in the obese group with control.Similar results were obtained by Gil-Campos et al. [20]who reported a significant increase in serum triglycerides in obese group.Similar results were obtained by Isabelle et al. [21] who reported a significant increase in plasma cholesterol and triglyceride concentrations in obese subjects. Cholesterolemia and triglyceridemia were the result of an increase in lipid concentrations in all lipoprotein fractions.

The results of the current work demonstrated that, statistically significant increase in leptin concentrations was observed in obese subjects when compared to the control group $(\mathrm{P} \leq 0.001)$,in addition to significant positive correlation between serum leptin and BMI $(\mathrm{P} \leq 0.001)$.

In the same line with our results, Crowley [22] stated that,leptin levels were markedlyelevated in obese humansthan in lean individuals and directly associated with adiposity and asleptin inhibits gastric ghrelin secretion, accordingly ghrelin has lowconcentrations in obese subjects. Also, Gil-Campos et al. [20] noticed that fasting leptin levels were positively associated with BMI. Current results come like what was found inChan et al. [23], suggesting that leptin might be the important factor for the negative feedback regulation of ghrelin and leptin was elevated in obese subjects compared with normal weight ones.

In the present study, as regard the results of the levels of ghrelin were significantly reduced in obese post-menopausal group when compared to control group $(\mathrm{P} \leq 0.001)$ and also, significant negative correlation between ghrelin and $\mathrm{BMI}(\mathrm{P} \leq 0.001)$. Theseresults were supported by a study carried by Carlson et al. [24]in which ghrelin levels were found to be significantly higher in normal weight women, 15, 60 and 120 minutes post-meal when compared to overweight/obese womenand also goes hand in hand with the study carried by Karczewska-Kupczewskaet al. [25]who found that in the fasting state, serum ghrelin was higher in normal-weight women than in overweight/obese women. Similar findings were reported by several studies which stated that basal ghrelin levels were significantly lower in overweight/obese group compared with normal weight.Katsuki et al. [26], Erdmann et al. [27], Esplund et al. [28], Le Roux et al. [29] and Erdie-Lalena[30] detected that ghrelin secretion increases in anorexia and cachexia and was reduced in obesity, which it might act as a signal of the metabolic balance to the CNS and might contribute to these conditions as either compensatory or causative element.Also, Doogue et al. [31] concluded that plasma ghrelin concentrations were found to be inversely associated with obesity and food intake.However, according to Sondergaard et al. [32], obesity was a strong predictor of low basal ghrelin concentrations, and it had a key role in regulating fasting plasma ghrelin suppression, apart from being diabetic or not. In accordance with the results of the current study, Shiiyaet al. [33]found that fasting plasma ghrelin concentrations were negativelyassociated with BMI in both non-diabetic and diabetic patients. Theyfound that overweight/obese subjects had lower fasting plasma ghrelinconcentrations than normal weight subjects. Additionally, Anderworldet al. [34], who reported a significant association between fasting ghrelin and BMI.

Comparable results were elucidated by Barazzoni et al. [35]in obese and lean Caucasians and Beasley et al. [36]who found that overweight/obese individuals had lower ghrelin concentrations compared to normal weight individuals.In support of the same results, Daghestani [37] found that ghrelin concentrations decreased in overweight/obese Saudi females compared to lean ones; i.e. ghrelin levels were negatively associated with BMI.Castaneda et al. [38] suggested that ghrelin itself is not the key cause of obesity and stated whether potentially low levels of ghrelin in obesity represent an adaptation to the positive energy balance or an increased sensitivity to ghrelin remains an open question.Zou et al. [39] speculated that the lower ghrelin levels in obesity were part of negative feedback to inhibit appetite and body weight, but not the primary cause of obesity. Ghrelin plays an important role in the regulation of food intake. Therapeutic intervention with ghrelin in catabolic situation may induce a combination of enhanced food intake, increased gastric emptying and nutrient storage, so ghrelin agonists might address cachexia Constance et al. [40].

Present work revealed significant negative correlation was detected between the ghrelin and leptin levels $(\mathrm{r}=0.603, \mathrm{P} \leq$ 0.001 ). This finding was in agreement with the study done by Tschop et al. [41]. They showed that obese individuals have lower ghrelin serum concentrations than healthy controls. Furthermore, low concentrations of ghrelin were thought to be consequence of elevated serum levels of leptin, because fasting serum ghrelin concentrations were negatively correlated with fasting serum concentrations of leptin. Decreased ghrelin level in obesity might be due to a secondary response to overeating. Similarly, BilginYüksel[42] who stated that lower serum ghrelin levels in obese subjects compared to individuals with normal body weight and showing a negative correlation with BMI, while leptin levels are increased. These findings have been interpreted as pointing towards a co-regulatory role of ghrelin and the upper gastrointestinal tract on food intake. Ghrelin increases gastric and intestinal motility. Leptin and ghrelin appear to have a negative regulatory role on the release and activity of each other. The weight reducing effect of leptin was not exercised only on the hypothalamic centers but also by the peripheral inhibitory effects on secretion and activities of ghrelin.Matching to our results, Vincent [43] demonstrated that In elderly people relatively large amounts of fat increase the satiety signal from Glucagon-Like peptide1 (GLP-1) and lower the acylated to desacylated ratio of ghrelin, consequently decreasing hunger. This condition may lead to a reduction in calorie intake, so positive energy balance lower ghrelin levels as a result of obesity, but not a cause of obesity.

The previous findings were debated by Bennetteet al. [44]who denoted that ghrelin had no association with obesity, and might not be causally involved in its development. 


\section{International Journal of Science and Research (IJSR) \\ ISSN (Online): 2319-7064}

Index Copernicus Value (2013): 6.14 | Impact Factor (2014): 5.611

Moreover, Pacificoet al. [45] found out that hyperinsulinemia resulted in a marked decrease in plasma ghrelin and this decrease was related to insulin sensitivity in both normal weight and overweight/obese subjects.

\section{Conclusions}

We proved that leptin concentrationsweresignificantly higher in postmenopausal obese group than in lean group, while in both measured groups the levels of circulating ghrelin werelower in the group of obese patients in comparison with the other group.As regards the ghrelin levels were negatively correlated with BMI in addition to significant positive correlation between leptin and BMI.Also, present study revealed significantnegative correlation was detectedbetween both hormones levels.From these results, the reduction inthe ghrelin together withthe increase in leptin levels probably fails tosuppress appetite in obese patients. Leptin concentration could be considered a good marker of the amount of body fat in obese conditions and could be used as a line of treatment.Thus, we recommend increasingnumber of patients and controls for better statistical analysis. Further studies are required to explain the etiology of leptin in obesity and/ orto investigate the effect of ghrelin deficiency in individuals with obesity.Further studies are needed to explain the role of measuring ghrelin for assessing the nutritional status. Further investigation of the impact of circulating leptin on fuel metabolism after food and macronutrient intake is needed.Finally, exploration of whether recombinant leptin or ghrelin antagonist is a potential therapeutic target for obesity in the future as inexpensive replacement therapy.

\section{References}

[1] Burger KS andBerner LA (2014): A functional neuroimaging review of obesity, appetitive hormones and ingestive behavior. Physiology \& Behavior; 136: 121-7.

[2] Comninos AN, Jayasena CN and Dhillo WS (2014): The relationship between gut and adipose hormones, and reproduction. Hum. Reprod. Update; 20 (2): 15374.

[3] Pan H, Guo J and $\mathrm{Su} \mathrm{Z}$ (2014): Advances in understanding the interrelations between leptin resistance and obesity. Physiology \& Behavior; 130: 157-169.

[4] Mohamed WS, Hassanien MA and Sayed KE (2014): Role of Ghrelin, Leptin and Insulin Resistance in Development of MetabolicSyndrome in Obese Patients. EndocrinolMetab Synd., 3: 122.

[5] SharifiF, Mahdi Y, Abdolreza E, Nouraddin M, and Zahra S (2013): Acylated ghrelin and leptinconcentrations in patients with type 2 diabetes mellitus, people withprediabetes and first degree relatives of patients with diabetes, acomparative study. Journal of Diabetes \& Metabolic Disorders; 6581-1251.

[6] Strohacker K, McCaffery JM, MacLean PS and Wing RR (2013):Adaptations of leptin, ghrelin or insulin during weight loss as predictors of weight regain: a review of current literature.International Journal of Obesity; 10.1038/118.
[7] Rőszer T, Józsa T, Kiss-Tóth ED, De Clerck N andBalogh L (2014): Leptin receptor deficient diabetic $(\mathrm{db} / \mathrm{db})$ mice are compromised in postnatal bone regeneration. Cell and Tissue Research; 356 (1): 195 206.

[8] Zhang L, Lu M, Yuan L, Lai W and Wang Y (2014): Association of leptin gene-2548 G/A polymorphism with obesity: a meta-analysis. Wei Sheng Yan Jiu (in Chinese); 43 (1): 128-32.

[9] Sanchez-Garrido MA and Tena-Sempere M (2013): Metabolic control of puberty: Roles of leptin and kisspeptins. HormBehav., 64 (2): 187-94.

[10] Ye XL and Lu CF (2013): Association of polymorphisms in the leptin and leptin receptor genes with inflammatory mediators in patients with osteoporosis. Endocrine., 44 (2): 481-8.

[11] Martins MC, Lima FL and Fonseca A (2012):Relationship between leptin and body mass and metabolic syndrome in an adult population. Rev Port Cardiol., 31: 711-719.

[12] Oswal A and Yeo G (2010): Leptin and the control of body weight: A review of its diverse central targets, signaling mechanisms, and role in the pathogenesis of obesity. Obesity; 18 (2): 221-9.

[13] Christine D (2013): Structure and physiological actions of ghrelin.Laboratory of Pathophysiological and Nutritional Biochemistry;Volume 518909, 25 pages.

[14] Sato T, Nakamura Y, Shiimura Y, Ohgusu H, Kangawa $\mathrm{K}$ and Kojima M (2012): Structure, regulation and function of ghrelin. J. Biochem., 151(2):119-128.

[15] Verhulst PJ andDepoortere I(2012): Ghrelin's second life: from appetite stimulator to glucose regulator. World J Gastroenterol., 18(25):95-3183.

[16]Kollias H(2011): Leptin, Ghrelin and Weight Loss: It's Complicated precision.Nutrition; 95(11):5037-5044.

[17] Perello M, Scott MM, Sakata I, Lee CE, Chuang JC, Osborne-Lawrence S, Rovinsky SA, Elmquist JK andZigman JM (2012): Functional implications of limited leptin receptor and ghrelin receptor co-expression in the brain. The Journal of Comparative Neurology; 520 (2): 281-94.

[18] Al-Hakeim HK and Ali MM (2012): Low ghrelin level is associated with poor control and bad prognosis parameters in obese diabetic patients. Journal of Diabetology; 1-5.

[19]Heppner KM and Tong J (2014): Mechanisms in endocrinology: Regulation of glucose metabolism by the ghrelin system: Multiple players and multiple actions. European Journal of Endocrinology / European Federation of Endocrine Societies; 171 (1): R21-32.

[20] Gil-Campos M, Aguilera CM, Canete R and Gil A (2006): Ghrelin: a hormone regulating food intake and energy homeostasis. Br J Nutr., 96(2):201-26.

[21] Isabelle C, Estelle $T$ and Louis P(2005): Influence of obesity on plasma lipid and lipoprotein concentrations. AJVR;66:81-86.

[22] Crowley VE (2008):Overview of human obesity and central mechanisms regulating energy homeostasis.AnnClinBiochem., 45: 245-255.

[23] Chan JL, Bullen J, Lee JH, Yiannak-Ouris $\mathrm{N}$ and Mantzoros CS. (2004):Ghrelin levels are not regulated by recombinant leptin administration and/or threedays of 


\section{International Journal of Science and Research (IJSR) \\ ISSN (Online): 2319-7064 \\ Index Copernicus Value (2013): 6.14 | Impact Factor (2014): 5.611}

fasting in healthy subjects. J ClinEndocrinolMetab., 89: 335-343.

[24] Carlson JJ, Turpin AA, Wiebke G and Hunt SC. (2009):Pre- and post-prandial appetite hormone levels in normal weight and severely obesewomen. NutrMetab., 11(6): 32-37.

[25] Karczewska-Kupczewska M, Straczkowski M and Adamska A. (2010):Increased suppression of serum ghrelin concentration by hyperinsulinemia inwomen with anorexia nervosa. Eur J Endocrinol., 28(2): 352360 .

[26] Katsuki A, Urakawa H, Gabazza EC, Murashima S, Nakatani K, TogashiK, Yano Y, Adachi Y and Sumida Y (2004):Circulating levels of active ghrelin is associated with abdominal adiposity,hyperinsulinemiaand insulin resistance in patients with type 2 diabetes mellitus. EurJ Endocrinol., 151(5): 573-577.

[27]Erdmann J, Lippl F, Wagenfeil S and Schusdziarra V. (2005):Differential association of basal postprandial plasma ghrelin, leptin, insulin andtype 2 diabetes. Diabetes; 54: 1371-1378.

[28] Espelund U, Hansen TK, Hojlund K and Beck-Nielsen H. (2005):Fasting unmasks a strong inverse association between ghrelin and cortisol in serum: Studies in obese and normal weight subjects. J ClinEndocrinolMetab., 90: 741-746.

[29]Le Roux CW, Patterson $M$ and Vincent RP (2005):Postprandial plasma ghrelin is suppressed proportional to meal calorie in normalweight but not obese subjects. J ClinEndocrinolMetabol., 90: 10681071.

[30] Erdie-Lalena CR (2006):Ghrelin levels in very young children with Prader-Willi syndrome. J Pediatr., 149:199-204.

[31] Doogue MP, Begg EJ and Moore MP (2009):Metformin increases plasma ghrelin in type 2 diabetes. $\mathrm{Br} \mathrm{J}$ ClinPharmacol., 68(6):875-882.

[32] Sondergaard E, Gormsen LC, Nelleman B, Vestergaard ET, ChristiansenJS and Nielsen S (2008):Visceral fat mass is a strong predictor of circulating ghrelin levels in premenopausalwomen. Eur J Endocrinol., 60(3): 375379.

[33] Shiiya T, Nakazato M, Mizuta M, Date Y, Mandal MS, Tanaka M, NozoeS, Hosoda H, Kangawa $\mathrm{K}$ and Matsukura S (2002):Plasma ghrelin levels in lean and obese humans and the effect of glucose on ghrelinsecretion. J ClinEndocrinolMetabol., 87: 240244.

[34] Anderworld C, Brabant G, Bernroider E, Horn R, Breham A, WaldhauslW and Roden M. (2003):Insulindependent modulation of plasma ghrelin and leptin in concentrations is lesspronounced in type 2 diabetic patients. Diabetes; 52(7): 1792-1798.

[35]Barazzoni R, Zanetti $\mathrm{M}$ and Ferreiral (2007):Relationships between desacylated and acylated ghrelin and insulin sensitivity inmetabolic syndrome. J ClinEndocrinolMetab., 92: 3935-3940.

[36] Beasley JM, Ange BA,Anderson CA, Miller ER, Holbrook JT and AppelLJ (2008): Characteristics associated with fasting appétit hormones (obestatin, ghrelin andleptin).Obesity; 7(2): 349-354.
[37]DaghestaniMH(2009): A preprandial and postprandial plasma levels ofghrelin hormone in lean, overweight and obese Saudi females.Journal of King Saud University (Science); 21, 119-124.

[38] Castaneda TR, Tong J, Datta R, Culler M and Tschop MH (2010):Ghrelin in the regulation of body weight and metabolism. Frontiers inNeuroendocrinology; 31: 44-60.

[39]Zou CC, Liang L and Zhao ZY (2008):Factors associated with fasting plasma ghrelin levels in children and adolescents.World J Gastroentrol., 14(5): 790-794.

[40] Tshop M, Smiley DL and Heiman ML(2008):Circulating Ghrelin levels are decreased in human obesity diabetes; 50:707-9.

[41] Constance CH,Karolin M,Annette G(2009): Ghrelin a novel generation of anti- obesity drug. European peptide Society; 15:711-730.

[42] Bilgin Y(2009):Neuroendocrinal control of obesity. J Clin Res Ped Endo., (Suppl 1):58-6.

[43] Vincent E(2010):Ghrelin, hunger, obesity, and aging .Aging sciences-Anti Aging Firewalls; 15.

[44] Benette NR, Boyne MS, Cooper RS, Royal-Thomas TY, Benette FA, LukeA, Wilks RJ and Forrester TE (2008):Impact of adiponectin and ghrelin on incident glucose tolerance and on weightchange. Clin Endocrinol.,70(3): 408-414.

[45] Pacifico L, Poggiogalle E, Costantino F and Anania C (2009):Acetylated and non-acetylated ghrelin levels and their association with insulinresistance in obese and normal weight children with metabolic syndrome. Eur JEndocrinol., 22(3): 288-297. 